\title{
Muscle fat infiltration assessed by total psoas density on computed tomography predicts mortality in cirrhosis
}

\author{
Maria Kalafatelia, Andreas Karatzas ${ }^{b}$, Georgios Tsiaoussis ${ }^{a}$, Efstratios Koutroubakis ${ }^{a}$, \\ Paraskevi Tselekounia, Nikolaos Koukias ${ }^{\mathrm{a}}$, Christos Konstantakis ${ }^{\mathrm{a}}$, Stelios Assimakopoulosc, \\ Charalambos Gogosc, Konstantinos Thomopoulos ${ }^{a}$, Christina Kalogeropouloub, Christos Triantos ${ }^{a}$ \\ University Hospital of Patras, Greece
}

\section{Abstract}

\section{Introduction}

Malnutrition is a common complication of cirrhosis. The prevalence of malnutrition ranges from 50-90\% and is proportionally related to the severity of liver disease [1].

Departments of a Gastroenterology (Maria Kalafateli, Georgios Tsiaoussis, Efstratios Koutroubakis, Paraskevi Tselekouni, Nikolaos Koukias, Christos Konstantakis, Konstantinos Thomopoulos, Christos

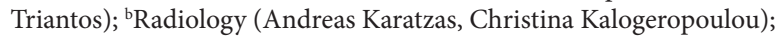
'Internal Medicine (Stelios Assimakopoulos, Charalambos Gogos), University Hospital of Patras, Patras, Greece

Conflict of Interest: None

Correspondence to: Christos Triantos, MD, D. Stamatopoulou 4, Rio 26504, Patras, Greece, e-mail: chtriantos@hotmail.com

Received 15 September 2017; accepted 26 January 2018; published online 4 April 2018

DOI: https://doi.org/10.20524/aog.2018.0256
It constitutes an independent predictor of mortality in patients with liver cirrhosis [2] and has been associated with detrimental early postoperative outcomes following liver transplantation [3].

The etiology of malnutrition in chronic liver disease (CLD) is considered to be multifactorial. Abnormal nutrient and caloric intake, decreased intestinal absorption and metabolic disturbances are all common in the CLD setting [4] and have been proposed as some of the major determinants that adversely affect nutritional status. Malnutrition is defined as a deficiency or imbalance in the intake of energy and/or nutrients and its diagnosis is based on the presence of at least 2 of the following 6 criteria: weight loss, inadequate energy intake, loss of muscle mass, loss of subcutaneous fat, fluid accumulation and diminished functional status [5]. Sarcopenia results from the impaired nutritional intake and, although not synonymous, its definition overlaps that of malnutrition. Several groups have attempted to define sarcopenia [6-8], but there is still no consensus among experts. According to 
Delmonico et al the definition of sarcopenia was based on dual energy X-ray absorptiometry measuring whole and regional body composition [9]. Computed tomography (CT) and magnetic resonance imaging are considered to be the gold standards for estimating muscle mass and muscle fatty infiltration for research purposes [6]. CT cross-sectional analytic morphometry has been used to correlate muscle mass with clinical outcomes in end-stage CLD. According to most of these studies, decreased muscle size is an independent predictor of mortality, both in stable cirrhosis [10] and on the liver transplantation waiting list $[11,12]$, and it adversely affects outcomes in the post-transplant setting [3,13-15]. However, there is scarce evidence concerning the prognostic role of muscle fatty infiltration (the other component of sarcopenia) in CLD. In a recent study [16] the prognostic significance of sarcopenia, sarcopenic obesity and myosteatosis was investigated in 678 patients with cirrhosis. The authors reported both sarcopenia and myosteatosis as independent predictors of mortality in cirrhosis. However, the cutoff values used for the definition of sarcopenia/myosteatosis were derived from studies that included oncologic patients. These results were not validated in CLD patients. Thus, we conducted this retrospective cohort study to evaluate the impact of muscle attenuation, measured by CT scan as an index of muscle fatty infiltration, on the overall survival of patients with cirrhosis.

\section{Patients and methods}

\section{Patients}

Ninety-eight patients with liver cirrhosis who attended the hepatology outpatient clinics between 2005 and 2011 and underwent an abdominal CT scan for any reason during the study period, which included the fourth lumbar (L4) section, were retrospectively enrolled in the analysis. In our center, cross-sectional imaging is commonly performed in patients with cirrhosis for diagnosis of hepatocellular carcinoma (HCC), differential diagnosis of gastrointestinal symptoms common in this setting, and/or pre-transplant evaluation. Patients with HCC beyond the Milan criteria were excluded from the study. The study was approved by the local hospital's ethics committee and conformed to the ethical guidelines of the 1975 Declaration of Helsinki.

\section{Demographic, clinical and biochemical characteristics}

Data were recovered from the review of medical charts and included sex, age, height, weight, etiology of cirrhosis, presence of ascites or encephalopathy, liver biochemistry, and presence of HCC. None of the patients had diabetes mellitus. Survival data were recovered from medical charts or clinical correspondence. The severity of liver disease was assessed by the Child-Pugh class and score and the Model for End-stage Liver Disease (MELD). The presence of ascites was confirmed with both clinical and radiological findings.

\section{CT image analysis}

CT scans for routine diagnostic purposes were used for the assessment of total psoas muscle area (TPA) and density (ATPD). All CT scans were performed in the same scanner (GE Lightspeed 16x) and images were analyzed on a GE workstation in consensus by two radiologists (AK and CK), blinded to the patients' outcomes. Freehand areas of interest (ROIs) were drawn covering the entire cross-sectional areas of the left and right psoas muscles at the level of the L4/L5 intervertebral disc on precontrast images. This provided the values of area in $\mathrm{mm}^{2}$ and density in Hounsfield units (HU) of each psoas muscle at this level. The area of the resulting enclosed regions was then computed to generate the cross-sectional area of both psoas muscles by summing the areas of each (Fig. 1). To assess fatty infiltration of the psoas muscles, their mean density was calculated (left psoas muscle density + right psoas muscle density/2), with lower HU reflecting higher fat infiltration [9].

\section{Statistical analysis}

Numerical data were expressed as mean \pm standard deviation if the distribution was normal, or median with interquartile range if not, and categorical data were represented as counts and percentages. All variables were tested for normal distribution using the Kolmogorov-Smirnov test. Categorical variables were tested using the chi-square and Fisher's exact test. Continuous variables with and without normal distribution were compared using Student's $t$-test or the Mann-Whitney $U$ test, respectively. Spearman's correlation coefficient $(r)$ analysis was used for correlation between L4-TPA or L4-ATPD and baseline characteristics. Multivariate analysis of factors predicting TPA and ATPD values was performed by linear regression. For the survival analysis, we calculated the months

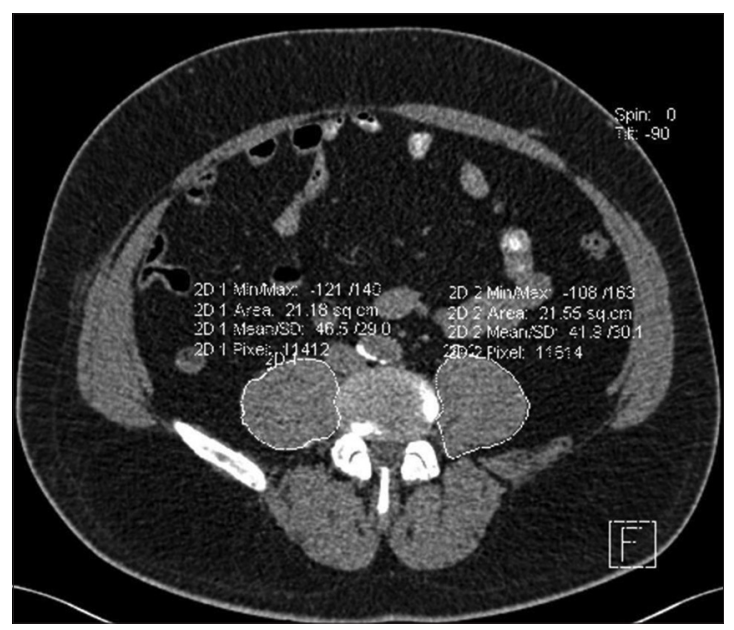

Figure 1 Multiplanar reconstruction images were used in the precontrast examination of these patients to determine the L4/L5 level of the lumbar spine. In the axial plane at the level of the intervertebral disk a freehand region of interest was drawn around each psoas muscle. The total cross-sectional area of the two psoas muscles and the mean $\mathrm{HU}$ value were then calculated 
from the CT scan to death. Univariate and multivariate Cox regression analysis was used to identify independent predictors for overall survival. Kaplan-Meier analysis (log-rank test) was used to evaluate the impact of the lowest L4-ATPD quintile on overall survival. The discriminative ability of L4-ATPD to predict 12 -month mortality was assessed by receiver operating characteristic (ROC) analysis. The L4-ATPD value that maximized the sum of sensitivity and specificity (i.e., that with the highest Youden's index) was considered as the best cutoff. The results are presented as hazard ratios (HR) with 95\% confidence intervals (CI). Significance testing was two-sided and based on a P-value $<0.05$. Analysis was performed using the SPSS statistical package (version 22.0, IBM, New York, NY, USA) and MedCalc for Windows (version 12.5, MedCalc Software, Ostend, Belgium).

\section{Ethical guidelines}

The study was reviewed and approved by the ethics committee of the University Hospital of Patras. All study participants, or their legal guardian, provided informed written consent prior to study enrolment.

\section{Results}

The baseline characteristics of the study population are shown in Table 1. The etiologies of cirrhosis were alcohol $(\mathrm{n}=45,45.9 \%)$, viral hepatitis $(\mathrm{n}=23,23.4 \%)$, a combination of alcohol and viral hepatitis $(\mathrm{n}=12,12.2 \%)$, autoimmune liver disease $(n=8,8.2 \%)$, and other causes $(n=10,10.2 \%)$.

\section{Correlation of L4-TPA with baseline characteristics}

In the univariate analysis, TPA had a positive, although weak, correlation with height $(r=0.5, \mathrm{P}<0.001)$, weight $(r=0.566, \quad \mathrm{P}<0.001)$, body mass index (BMI) $(r=0.28$, $\mathrm{P}=0.008)$, and ATPD $(r=0.415, \mathrm{P}<0.001)$. Male patients had higher TPA values than females (median: $2022 \pm 719$ vs. $1264 \pm 482$; $\mathrm{P}<0.001$ ). No correlation with the severity of liver disease was found, whether assessed by Child-Pugh or MELD scores. However, sex-stratified analysis showed a significant correlation with Child-Pugh score $(r=-0.27, \mathrm{P}=0.024)$ and serum sodium ( $r=0.304, \mathrm{P}=0.017)$ in male patients (Fig. 2 ). In the multivariate linear regression analysis, which included sex, BMI, ATPD and Child-Pugh score, male sex $(b=0.54$, 95\%CI 614.56-1114.11; $\mathrm{P}<0.001)$, high BMI $(b=0.24,95 \% \mathrm{CI}$ 14.16-64.84; $\mathrm{P}=0.003)$ and increased L4-ATPD $(\mathrm{b}=0.4$, 95\%CI 15.42-35.08; $\mathrm{P}<0.001)$ were predictors of L4-TPA. In another model that included the individual components of the Child-Pugh score, rather than the composite index, male sex $(b=0.557,95 \%$ CI 690.42-1297.74; $\mathrm{P}<0.001)$, high BMI $(b=0.274,95 \% C I$ 17.3-76.05; $\mathrm{P}=0.002)$, increased L4ATPD ( $b=0.4,95 \%$ CI 14.36-35.79; $\mathrm{P}<0.001)$, normal serum sodium $(\mathrm{b}=0.18,95 \% \mathrm{CI} 1.024-55.39 ; \mathrm{P}=0.042)$ and no ascites
Table 1 Baseline characteristics of the study population at the time of computed tomography scan

\begin{tabular}{|c|c|}
\hline Characteristic & Median (range) or $\mathrm{n}(\%)$ \\
\hline Age (years) & $63(27-93)$ \\
\hline $\operatorname{Sex}(M / F)$ & $71 / 27(72.4 / 27.6)$ \\
\hline Height $(\mathrm{cm})$ & $167(145-187)$ \\
\hline Weight (kg) & $75.9(45-140)$ \\
\hline BMI $\left(\mathrm{kg} / \mathrm{m}^{2}\right)$ & $26(17-45.2)$ \\
\hline HCC & $14(14.3)$ \\
\hline INR & $1.3(0.86-3.04)$ \\
\hline Total bilirubin (mg/dL) & $1.29(0.3-19.2)$ \\
\hline Albumin (g/dL) & $3.5(2.1-4.7)$ \\
\hline Creatinine (mg/dL) & $0.9(0.5-3.1)$ \\
\hline Sodium $(\mathrm{mmol} / \mathrm{L})$ & $139(124-149)$ \\
\hline Ascites & $49(50)$ \\
\hline Encephalopathy & $5(5.1)$ \\
\hline $\mathrm{CP}$ class $(\mathrm{A} / \mathrm{B} / \mathrm{C})$ & $49 / 39 / 10(50.5 / 40 / 9.5)$ \\
\hline CP class & $7(5-13)$ \\
\hline MELD score & $11(6-29)$ \\
\hline L4-TPA $\left(\mathrm{mm}^{2}\right)$ & $2022(777-3806)$ \\
\hline L4-ATPD (HU) & $42.52(21.26-59.8)$ \\
\hline Follow up (months) & $45(1-140)$ \\
\hline
\end{tabular}

M/F, males/females; HCC, hepatocellular carcinoma; CP, Child-Pugh; INR, international normalized ratio; MELD, model for end-stage liver disease; TPA, total psoas area; $A T P D$, average total psoas density

$(b=-0.198,95 \% C I$ 32.84-530.48; $\mathrm{P}=0.027)$ were found significant.

\section{Correlation of L4-ATPD with baseline characteristics}

In the univariate analysis, ATPD was significantly correlated with age $(r=-0.222, \mathrm{P}=0.034)$, creatinine $(r=-0.41, \mathrm{P}<0.001)$, albumin ( $r=0.224, \mathrm{P}=0.035)$, and MELD score $(r=-0.218$, $\mathrm{P}=0.034)$, but not with BMI. There was no difference in ATPD between male and female subjects $(43.04 \pm 8.95$ vs. $41.6 \pm 13.1$, $\mathrm{P}=0.34)$. A moderately weak but significant correlation was also observed with TPA $(r=0.415, \mathrm{P}<0.001)$. This correlation was stronger in the subgroup of male patients $(r=0.538, \mathrm{P}<0.001)$, but was not significant in female patients $(r=0.22, \mathrm{P}=0.267)$. However, there was a wide variation of ATPD across individuals with the same TPA for both male and female patients (Fig. 3). Likewise, patients with the same MELD score demonstrated a wide range of ATPD values (Fig. 4). The multivariate linear regression analysis of the factors which presented statistically significant difference in the univariate analysis together with sex, showed that younger age $(b=-0.179,95 \% C I-0.32--0.009$; $\mathrm{P}=0.039)$, male sex $(\mathrm{b}=0.24,95 \% \mathrm{CI} 0.73-11.27 ; \mathrm{P}=0.026)$, lower creatinine levels $(b=-0.38,95 \% C I-17.17$ - $-6.26 ; P<0.001)$, and higher TPA $(b=0.59,95 \% \mathrm{CI} 0.006-0.013, \mathrm{P}<0.001)$ were independently positively associated with ATPD. 


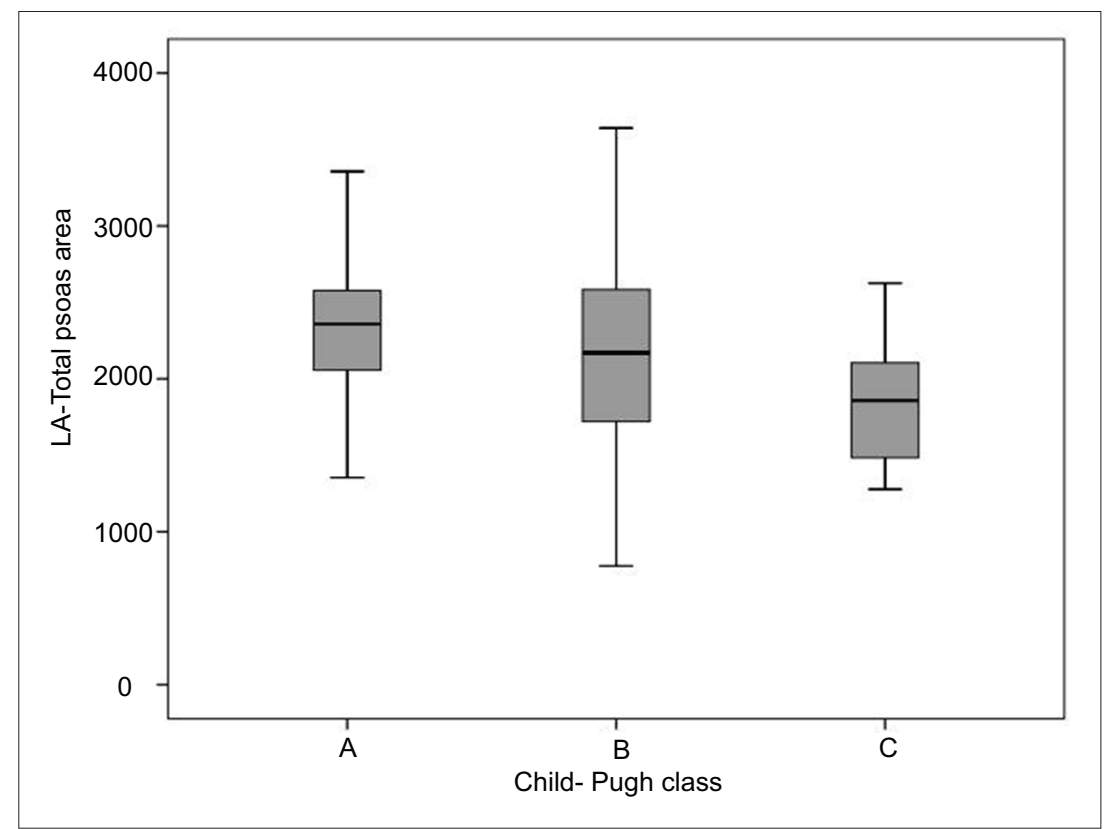

Figure 2 Box-plots of L4-total psoas area (L4-TPA) at different Child-Pugh classes in males (Child-Pugh A (median \pm interquartile range): $2359 \pm 641 \mathrm{~mm}^{2}$, Child-Pugh B: $2170.5 \pm 903 \mathrm{~mm}^{2}$, Child-Pugh C: $1858.5 \pm 661 \mathrm{~mm}^{2}$; Child-Pugh A vs. B P=0.213, Child-Pugh A vs. C P=0.05, Child-Pugh B vs. C $\mathrm{P}=0.128$ )

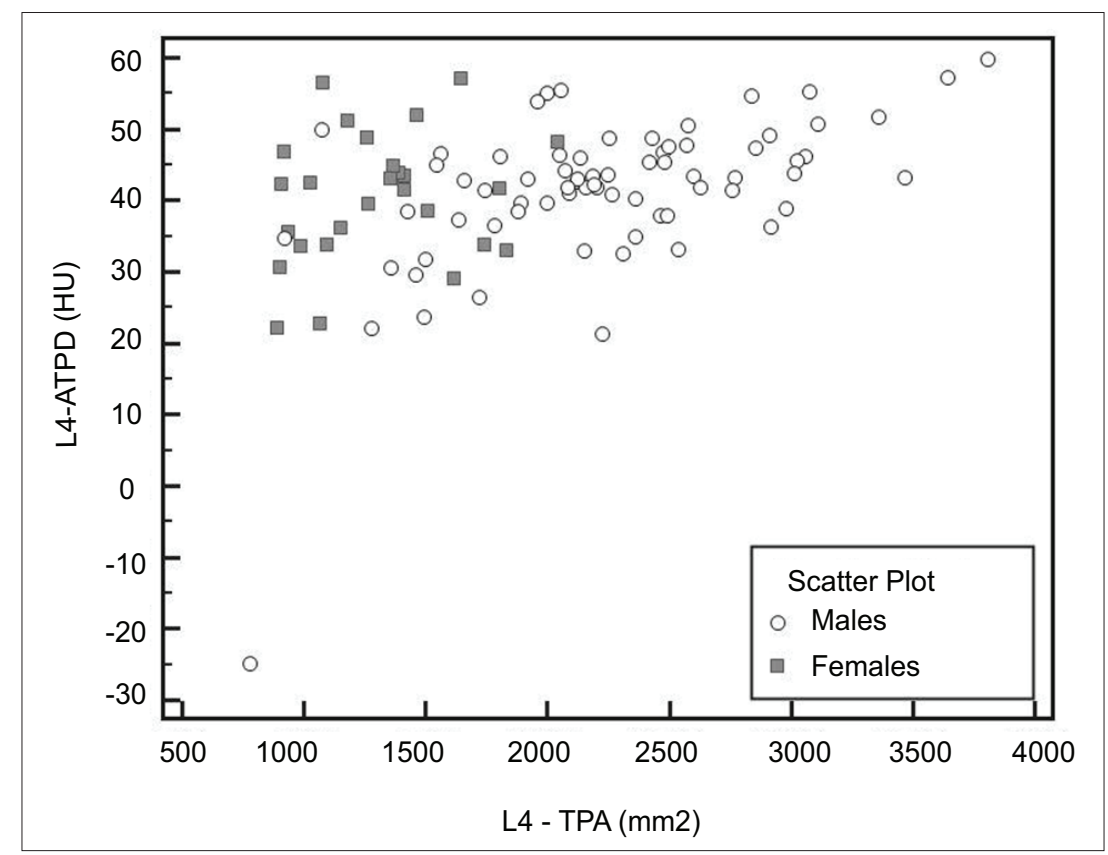

Figure 3 Scatter plot of L4-average total psoas density (ATPD) and L4-total psoas area (L4-TPA) in males and females

\section{Overall survival}

Fifty-four patients (55.1\%) died and 4 were lost to follow up. The causes of death were liver failure (55\%), HCC (15\%), acute gastrointestinal bleeding (5\%), sepsis (5\%), acute kidney injury (5\%), and other etiologies (15\%). Median overall survival was 31.5 (range 1-140) months and median follow up of surviving patients was 57 (range 2-130) months. The univariate and multivariate Cox regression analyses of the predictive factors for mortality are shown in Table 2. The value of L4-TPA was not predictive of the overall survival; thus, only ATPD was tested in the multivariate Cox regression analysis. In the multivariate analysis adjusted for age and sex, higher $\mathrm{CP}$ score (HR 1.2, 95\%CI: 1.04-1.41, P=0.014), lower ATPD (HR 0.967, 95\%CI: 0.937-0.997, $\mathrm{P}=0.034)$ and advanced age (HR 1.038, 95\%CI: $1.006-1.07, \mathrm{P}=0.018$ ) were independent predictors of 
mortality. Survival analysis of the L4-ATPD distribution in tertiles, quartiles and quintiles showed a lower survival rate for patients in the lowest quintile (ATPD $<34.48 \mathrm{HU}$ ) compared to patients in the other quintiles (median $36.5 \pm 41$ months vs. $48 \pm 38$ months; Fig. 5). There was no difference in survival between patients in the lowest tertile (or quartile) and patients in the other tertiles (or quartiles) of ATPD (data not shown).
The area under the ROC curve for L4-ATPD to predict 12-month mortality was 0.62 (95\%CI 0.51-0.69). The optimum cutoff for L4-ATPD to predict 12-month mortality was 43.14 HU (Youden index J: 0.2462, sensitivity: 76.5\%, specificity: $48.2 \%$, positive predictive value: $23.6 \%$, negative predictive value: $90.7 \%$, positive likelihood ratio: 1.47 , negative likelihood ratio: 0.5$)$.

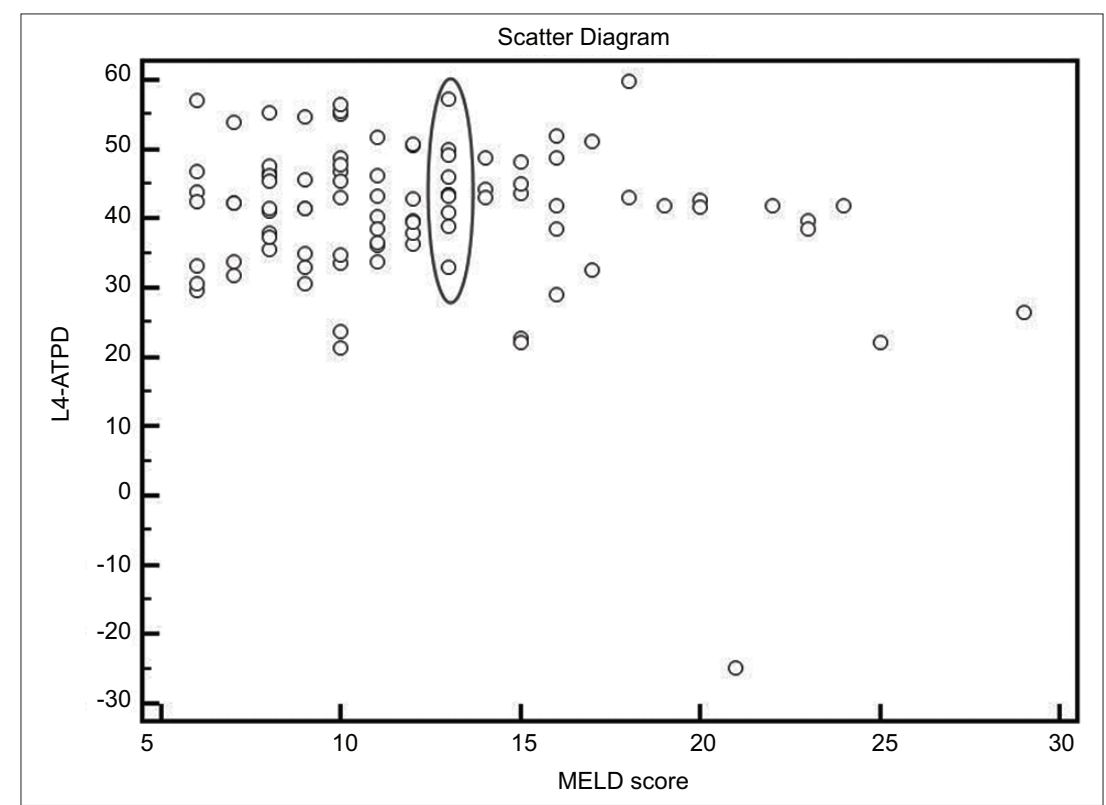

Figure 4 Scatter plot of L4-average total psoas density (ATPD) and model for end-stage liver disease (MELD) score. Patients with the same MELD score exhibit a wide range of ATPD values

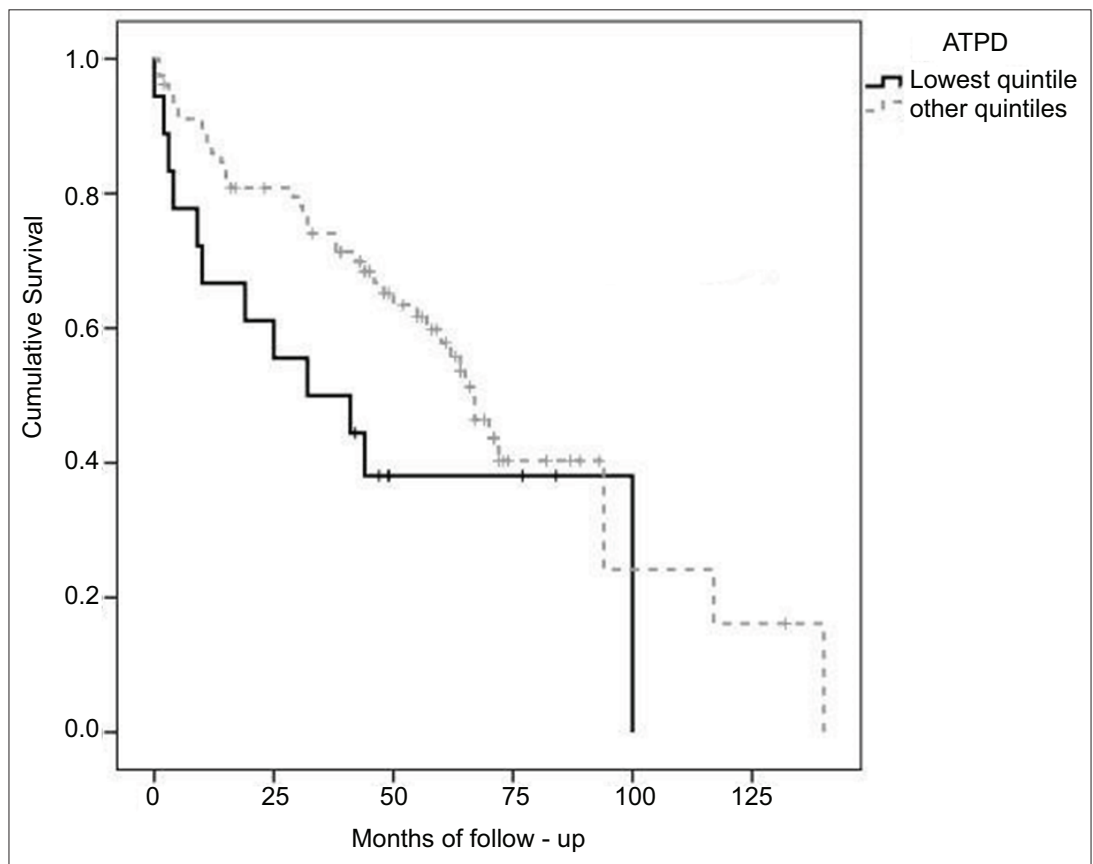

Figure 5 Kaplan-Meier survival plot of patients at the lowest L4-average total psoas density (ATPD) quintile versus the other quintiles (log rank=3.987, $\mathrm{P}=0.046$ ) 
Table 2 Univariate and multivariate analysis of factors predicting overall survival in patients with cirrhosis

\begin{tabular}{|c|c|c|c|c|}
\hline Factors & Dead $(n=54)$ & Alive $(\mathrm{n}=44)$ & $\begin{array}{c}\text { Univariate analysis } \\
\text { HR }(95 \% \mathrm{CI})\end{array}$ & $\begin{array}{c}\text { Multivariate analysis } \\
\text { HR }(95 \% \mathrm{CI})^{\mathrm{a}}\end{array}$ \\
\hline $\begin{array}{l}\text { Age (years), } \\
\text { median (range) }\end{array}$ & $\begin{array}{c}61 \\
(27-87)\end{array}$ & $\begin{array}{c}63 \\
(32-78)\end{array}$ & $\begin{array}{c}1.022 \\
(0.99-1.05)\end{array}$ & $\begin{array}{c}1.038 \\
(1.006-1.07)^{*}\end{array}$ \\
\hline $\begin{array}{l}\operatorname{Sex}(M / F) \\
n(\%)\end{array}$ & $\begin{array}{c}42 / 12 \\
(77.8 / 22.2)\end{array}$ & $\begin{array}{c}29 / 15 \\
(65.9 / 34.1)\end{array}$ & $\begin{array}{c}1.29 \\
(0.68-2.47)\end{array}$ & $\begin{array}{c}0.922 \\
(0.44-1.93)\end{array}$ \\
\hline $\begin{array}{l}\text { Height }(\mathrm{cm}) \text {, } \\
\text { median (range) }\end{array}$ & $\begin{array}{c}170 \\
(150-185)\end{array}$ & $\begin{array}{c}167 \\
(153-187)\end{array}$ & $\begin{array}{c}0.99 \\
(0.97-1.02)\end{array}$ & \\
\hline $\begin{array}{l}\text { Weight }(\mathrm{kg}) \text {, } \\
\text { median (range) }\end{array}$ & $\begin{array}{c}75.45 \\
(48-106.5)\end{array}$ & $\begin{array}{c}75 \\
(50-96)\end{array}$ & $\begin{array}{c}0.53 \\
(0.009-31.9)\end{array}$ & \\
\hline $\begin{array}{l}\mathrm{BMI}\left(\mathrm{kg} / \mathrm{m}^{2}\right) \\
\text { median (range) }\end{array}$ & $\begin{array}{c}24.83 \\
(19.33-35.08)\end{array}$ & $\begin{array}{c}26.89 \\
(19.53-32.27)\end{array}$ & $\begin{array}{c}0.99 \\
(0.93-1.06)\end{array}$ & \\
\hline \multicolumn{5}{|l|}{$\begin{array}{l}\text { Etiology of liver disease, } \\
\mathrm{n}(\%)\end{array}$} \\
\hline Alcohol & $\begin{array}{c}24 \\
(44.4)\end{array}$ & $\begin{array}{c}21 \\
(47.7)\end{array}$ & $\begin{array}{c}0.1 \\
(0.006-1.72)\end{array}$ & \\
\hline Viral hepatitis & $\begin{array}{c}14 \\
(25.9)\end{array}$ & $\begin{array}{c}7 \\
(15.9)\end{array}$ & $\begin{array}{c}0.12 \\
(0.012-1.19)\end{array}$ & \\
\hline $\begin{array}{l}\text { HCC, } \\
\text { n (\%) }\end{array}$ & $\begin{array}{c}13 \\
(24.1)\end{array}$ & $\begin{array}{c}1 \\
(2.3)\end{array}$ & $\begin{array}{c}2.056 \\
(1.08-3.9)^{*}\end{array}$ & $\begin{array}{c}1.87 \\
(0.89-3.96)\end{array}$ \\
\hline $\begin{array}{l}\text { Decompensation at first } \\
\text { presentation, } \mathrm{n}(\%)\end{array}$ & $\begin{array}{c}35 \\
(63.6)\end{array}$ & $\begin{array}{c}20 \\
(36.4)\end{array}$ & $\begin{array}{c}1.696 \\
(0.965-2.982)\end{array}$ & \\
\hline $\begin{array}{l}\text { INR, } \\
\text { median (range) }\end{array}$ & $\begin{array}{c}1.3 \\
(0.96-2.68)\end{array}$ & $\begin{array}{c}1.38 \\
(0.97-2.48)\end{array}$ & $\begin{array}{c}1.61 \\
(0.79-3.28)\end{array}$ & \\
\hline $\begin{array}{l}\text { Total bilirubin }(\mathrm{mg} / \mathrm{dL}) \text {, } \\
\text { median (range) }\end{array}$ & $\begin{array}{c}1.55 \\
(0.6-9.1)\end{array}$ & $\begin{array}{c}1.08 \\
(0.4-4.9)\end{array}$ & $\begin{array}{c}1.07 \\
(0.98-1.17)\end{array}$ & \\
\hline $\begin{array}{l}\text { Albumin }(\mathrm{g} / \mathrm{dL}) \\
\text { median (range) }\end{array}$ & $\begin{array}{c}3.35 \\
(2.1-4.7)\end{array}$ & $\begin{array}{c}3.6 \\
(2.4-4.5)\end{array}$ & $\begin{array}{c}0.578 \\
(0.346-0.967)^{*}\end{array}$ & \\
\hline $\begin{array}{l}\text { Creatinine }(\mathrm{mg} / \mathrm{dL}) \text {, } \\
\text { median (range) }\end{array}$ & $\begin{array}{c}0.9 \\
(0.6-2.1)\end{array}$ & $\begin{array}{c}0.9 \\
(0.6-1.2)\end{array}$ & $\begin{array}{c}1.67 \\
(0.66-4.24)\end{array}$ & \\
\hline $\begin{array}{l}\text { Sodium }(\mathrm{mmol} / \mathrm{L}) \text {, } \\
\text { median (range) }\end{array}$ & $\begin{array}{c}138.5 \\
(125.3-149)\end{array}$ & $\begin{array}{c}139 \\
(129.5-147)\end{array}$ & $\begin{array}{c}0.99 \\
(0.93-1.05)\end{array}$ & \\
\hline $\begin{array}{l}\text { Ascites, } \\
\mathrm{n}(\%)\end{array}$ & $\begin{array}{c}31 \\
(57.4)\end{array}$ & $\begin{array}{c}18 \\
(40.9)\end{array}$ & $\begin{array}{c}1.56 \\
(0.9-2.69)\end{array}$ & \\
\hline $\begin{array}{l}\text { Encephalopathy, } \\
\text { n (\%) }\end{array}$ & $\begin{array}{c}3 \\
(5.6)\end{array}$ & $\begin{array}{c}2 \\
(4.5)\end{array}$ & $\begin{array}{c}1.54 \\
(0.48-4.98)\end{array}$ & \\
\hline $\begin{array}{l}\text { CP score, } \\
\text { median (range) }\end{array}$ & $\begin{array}{c}7 \\
(5-11)\end{array}$ & $\begin{array}{c}6 \\
(5-13)\end{array}$ & $\begin{array}{c}1.2 \\
(1.057-1.365)^{*}\end{array}$ & $\begin{array}{c}1.2 \\
(1.04-1.41)^{*}\end{array}$ \\
\hline $\begin{array}{l}\mathrm{CP} \text { class }(\mathrm{A} / \mathrm{B} / \mathrm{C}) \text {, } \\
\mathrm{n}(\%)\end{array}$ & $\begin{array}{c}20 / 28 / 6 \\
(37 / 51.9 / 11.1)\end{array}$ & $\begin{array}{c}29 / 11 / 4 \\
(65.9 / 25 / 9.1)\end{array}$ & $\begin{array}{c}3.02 \\
(1.66-5.47)^{*}\end{array}$ & \\
\hline $\begin{array}{l}\text { MELD score, } \\
\text { median (range) }\end{array}$ & $\begin{array}{c}11.5 \\
(6-23)\end{array}$ & $\begin{array}{c}11 \\
(6-23)\end{array}$ & $\begin{array}{c}1.05 \\
(0.99-1.1)\end{array}$ & \\
\hline $\begin{array}{l}\text { L4-TPA }\left(\mathrm{mm}^{2}\right) \text {, } \\
\text { median (range) }\end{array}$ & $\begin{array}{c}1959 \\
(906-3806)\end{array}$ & $\begin{array}{c}2000 \\
(1072-3111)\end{array}$ & $\begin{array}{c}1.00 \\
(0.99-1.1)\end{array}$ & \\
\hline $\begin{array}{l}\text { L4-ATPD (HU), } \\
\text { median (range) }\end{array}$ & $\begin{array}{c}42.84 \\
(21.26-59.8)\end{array}$ & $\begin{array}{c}43.04 \\
(32.63-57.06)\end{array}$ & $\begin{array}{c}0.968 \\
(0.944-0.993)^{*}\end{array}$ & $\begin{array}{c}0.967 \\
(0.937-0.997)^{*}\end{array}$ \\
\hline $\begin{array}{l}\text { Lowest quintile of L4- } \\
\text { ATPD }\end{array}$ & $\begin{array}{c}13 \\
(24.1)\end{array}$ & $\begin{array}{c}6 \\
(13.6)\end{array}$ & $\begin{array}{c}1.87 \\
(1.02-3.52)^{*}\end{array}$ & \\
\hline
\end{tabular}

${ }^{\mathrm{a}}$ Albumin was not included to avoid collinearity with CP score, ${ }^{*} \mathrm{P}<0.05, \mathrm{HR}$, hazard ratio; $95 \%$ CI, $95 \%$ confidence interval

M/F, males/females; HCC, hepatocellular carcinoma; PVT, portal vein thrombosis; CP, Child-Pugh; INR, international normalized ratio;

$M E L D$, model for end-stage liver disease; TPA, total psoas area; ATPD, average total psoas density 


\section{Discussion}

Our study clearly demonstrates the independent prognostic significance of muscle fat accumulation, a process involved in the muscle attenuation/sarcopenia that often complicates CLD patients, in the survival of patients with cirrhosis after a long follow-up period. However, the decrease in psoas muscle size, also considered a component of sarcopenia, was not correlated with survival. The main advantage of our study compared to others $[10,12,17]$ is the fact that we tested both features of sarcopenia (i.e., muscle mass loss and fat infiltration) and we did not focus only on muscle size. Evidence from our study (Fig. 2) supports a non-linear relationship between muscle mass and fat accumulation, suggesting an independent impact on survival that should be evaluated separately. We deliberately used muscle size and density as quantitative variables and avoided defining sarcopenia, taking into consideration the lack of specific cutoffs in patients with cirrhosis.

There are some differences between the findings of our study and those of two previous studies $[10,17]$ that also investigated the impact of sarcopenia on the survival of patients with cirrhosis which were not on the waiting list for liver transplantation. In both these studies, sarcopenia was assessed at the L3 vertebra level-L3-skeletal muscle index (SMI) - and the cutoff values used for its definition were based on the findings of a study that included patients with solid malignant tumors [18]. The aforementioned studies reported no correlation between sarcopenia and the severity of liver disease (defined by either MELD or Child-Pugh score); these findings were not in concordance with our study. We found a significant correlation between TPA and Child-Pugh score in males, confirming a previous observation [12] reporting that the prevalence of sarcopenia increased with the Child-Pugh class in male patients awaiting liver transplantation but not in females.

A decreased skeletal muscle index has been independently associated with overall mortality. However, there were significant differences from our study: a. The use of certain L3-SMI cutoff values for the definition of sarcopenia was not validated in patients with cirrhosis; $b$. The SMI was comprised of the cross-sectional areas of all muscles enclosed in the L3 region including the psoas muscle. In our study, we used only the psoas to evaluate muscle size. The psoas is a centrally located, deep muscle; it is easily recognizable, it does not require complex computations for its assessment and, most importantly, it is not influenced by abdominal distension in case of water retention [11]; c. The role of muscle fat infiltration was not evaluated in the previous studies, although the muscle depletion process of sarcopenia is by definition characterized by both muscle size decrease and fatty infiltration [9]; and d. The follow-up period in our study was longer (median 45 months) compared to other studies (median 15 [10] and 23 [17] months).

Skeletal muscle attenuation assessed by computed tomography is highly correlated with muscle triglyceride content in muscle biopsy [19] and is considered an objective measure of frailty, as it is related to age, inactivity and metabolic status [20]. It has also been associated with glucose intolerance, type II diabetes mellitus, proinflammatory mediators, impaired physical function and increased risk of disability [21-23]. The role of psoas muscle density (measured by analytic morphometry) as a predictor of poor outcome has also been evaluated in other chronic (non-liver) conditions. In 302 patients who underwent colectomy for colon cancer, psoas density was the sole predictor of surgical complications (OR 0.96, 95\%CI 0.94-0.99; P=0.004) [24]. In another study of 101 patients with stage III melanoma, psoas density, but not psoas area, was associated with disease-free survival (OR $0.398,95 \%$ CI $0.204-0.779$ ) and distant disease-free survival (OR 0.55, 95\%CI 0.349-0.866) [25]. As mentioned above, we found a significant correlation between muscle attenuation and liver disease severity. The mechanisms that link muscle fat infiltration and liver dysfunction might include a modulation in the pattern of proinflammatory cytokines (especially interleukin-6, tumor necrosis factor- $\alpha$, and C-reactive protein) and adipokines (leptin and adiponectin), observed in insulin resistance and type 2 diabetes [22,23], but the current evidence is very limited and further research is needed.

We found a significant discrepancy between ATPD values and MELD score, indicating that patients with the same liver function might have a wide range of ATPD values (Fig. 2). This indirectly reflects the independent impact of muscle fat infiltration on the overall mortality of patients with cirrhosis, confirmed by the multivariate analysis after adjustments to age, sex and liver disease severity. Notably, patients in the lowest quintile of ATPD had an almost twofold greater risk of death compared to patients in higher quintiles.

It is now widely accepted that prioritization of liver transplantation candidates based solely on the use of the MELD score can be suboptimal in certain clinical scenarios and runs the risk of misclassification of patients [26,27]. Durand et al [11] created a score (MELD/psoas score) that combined MELD score and transversal psoas muscle thickness/height (measured on a CT image) in a pre-MELD cohort $(n=186)$ and they tested its performance in a MELD-era cohort of patients waiting for liver transplantation $(\mathrm{n}=376)$. The c-statistic of the MELD-psoas was 0.82 (95\%CI 0.64-0.93), similar to that of the MELD-Na score and numerically slightly superior to that of the MELD score $(0.80$; 95\%CI 0.60-0.91). However, the difference did not reach statistical significance. The new score performed better in patients with refractory ascites and MELD score $<25$, but with no statistically significant difference compared to the MELD score. It remains to be elucidated whether psoas muscle density, as an objective measure of frailty, could predict waiting-list mortality, as our study did not included patients listed for liver transplantation.

The presence of malignancy is strongly associated with a complex metabolic profile in patients known as cancer cachexia [28]. The survival of patients with HCC has been negatively related to skeletal muscle index and muscle attenuation [29]. A recent study, which included patients with liver cirrhosis with or without concomitant HCC, evaluated the frequency and the clinical significance of sarcopenia and myosteatosis in a cirrhotic population [30]. In this study, a separate analysis was conducted for cirrhotics with and without HCC and no difference between these two groups emerged regarding the factors related to survival [30]. 
There are some limitations related to this study. Firstly, it was a single-center study with a retrospective design, so it needs to be validated prospectively in larger populations. Secondly, the inclusion of patients based on the availability of CT scans might have entailed a risk of selection bias. Thirdly, the baseline MELD score in this study was low in contrast with the high mortality rate. However, as the MELD score constitutes a prognostic model in cirrhosis that has been validated for short-term mortality (3 months in the original paper), this discrepancy may be related to the long follow-up period (median of 45 months) of our patients.

In conclusion, this study suggests that psoas muscle density measured on a single transverse CT image at the L4 level can predict mortality in patients with cirrhosis, independently of liver disease severity. Apart from the underlying liver disease, it seems that host factors have a detrimental impact on disease progression and should thus be taken into account in risk stratification. There is a need for early identification of malnourished/sarcopenic cirrhotic patients. The efficacy of nutritional interventions and exercise therapy in terms of nutritional status, muscle mass, muscle fat accumulation and subsequent outcomes in liver cirrhosis needs to be further investigated in large, prospective, randomized trials.

\section{Summary Box}

\section{What is already known:}

- Sarcopenia is one of the most common and adverse complications in patients with cirrhosis

- Computed tomography (CT) cross-sectional analytic morphometry has been used in a number of studies, which showed that decreased muscle sizes are associated with detrimental outcomes in end-stage chronic liver disease

- Evidence concerning the prognostic role of muscle fatty infiltration (as the other component of sarcopenia) in cirrhotic patients is scarce

\section{What the new findings are:}

- Increased psoas muscle fat infiltration measured on a single transverse CT image at the L4 level can predict mortality in patients with cirrhosis, independently of liver disease severity

- There is a great need for early identification of malnourished/sarcopenic cirrhotic patients

\section{References}

1. Cabré E, Gassull MA. Nutrition in liver disease. Curr Opin Clin Nutr Metab Care 2005;8:545-551.

2. Gunsar F, Raimondo ML, Jones S, et al. Nutritional status and prognosis in cirrhotic patients. Aliment Pharmacol Ther 2006;24:563-572.
3. Kalafateli M, Mantzoukis K, Choi Yau Y, et al. Malnutrition and sarcopenia predict post-liver transplantation outcomes independently of the Model for End-stage Liver Disease score. J Cachexia Sarcopenia Muscle 2017;8:113-121.

4. O'Brien A, Williams R. Nutrition in end-stage liver disease: principles and practice. Gastroenterology 2008;134:1729-1740.

5. White JV, Guenter P, Jensen G, Malone A, Schofield M; A.S.P.E.N. Board of Directors. Consensus statement: Academy of Nutrition and Dietetics and American Society for Parenteral and Enteral Nutrition: characteristics recommended for the identification and documentation of adult malnutrition (undernutrition). JPEN J Parenter Enteral Nutr 2012;36:275-283.

6. Cruz-Jentoft AJ, Baeyens JP, Bauer JM, et al; European Working Group on Sarcopenia in Older People. Sarcopenia: European consensus on definition and diagnosis: Report of the European Working Group on Sarcopenia in Older People. Age Ageing 2010;39:412-423.

7. Muscaritoli M, Anker SD, Argilés J, et al. Consensus definition of sarcopenia, cachexia and pre-cachexia: joint document elaborated by Special Interest Groups (SIG) "cachexia-anorexia in chronic wasting diseases" and "nutrition in geriatrics". Clin Nutr 2010;29:154-159.

8. Fielding RA, Vellas B, Evans WJ, et al. Sarcopenia: an undiagnosed condition in older adults. Current consensus definition: prevalence, etiology, and consequences. International working group on sarcopenia. J Am Med Dir Assoc 2011;12:249-256.

9. Delmonico MJ, Harris TB, Lee JS, et al; Health, Aging and Body Composition Study. Alternative definitions of sarcopenia, lower extremity performance, and functional impairment with aging in older men and women. J Am Geriatr Soc 2007;55:769-774.

10. Montano-Loza AJ, Meza-Junco J, Prado CM, et al. Muscle wasting is associated with mortality in patients with cirrhosis. Clin Gastroenterol Hepatol 2012;10:166-173, 173.e1.

11. Durand F, Buyse S, Francoz C, et al. Prognostic value of muscle atrophy in cirrhosis using psoas muscle thickness on computed tomography. J Hepatol 2014;60:1151-1157.

12. Tandon P, Ney M, Irwin I, et al. Severe muscle depletion in patients on the liver transplant wait list: its prevalence and independent prognostic value. Liver Transpl 2012;18:1209-1216.

13. Montano-Loza AJ, Meza-Junco J, Baracos VE, et al. Severe muscle depletion predicts postoperative length of stay but is not associated with survival after liver transplantation. Liver Transpl 2014;20:640-648.

14. Krell RW, Kaul DR, Martin AR, et al. Association between sarcopenia and the risk of serious infection among adults undergoing liver transplantation. Liver Transpl 2013;19:1396-1402.

15. Englesbe MJ, Patel SP, He K, et al. Sarcopenia and mortality after liver transplantation. J Am Coll Surg 2010;211:271-278.

16. Montano-Loza AJ, Angulo P, Meza-Junco J, et al. Sarcopenic obesity and myosteatosis are associated with higher mortality in patients with cirrhosis. J Cachexia Sarcopenia Muscle 2016;7:126-135.

17. Hanai T, Shiraki M, Nishimura K, et al. Sarcopenia impairs prognosis of patients with liver cirrhosis. Nutrition 2015;31:193-199.

18. Prado CM, Lieffers JR, McCargar LJ, et al. Prevalence and clinical implications of sarcopenic obesity in patients with solid tumours of the respiratory and gastrointestinal tracts: a population-based study. Lancet Oncol 2008;9:629-635.

19. Goodpaster BH, Kelley DE, Thaete FL, He J, Ross R. Skeletal muscle attenuation determined by computed tomography is associated with skeletal muscle lipid content. J Appl Physiol (1985) 2000;89:104-110.

20. Delmonico MJ, Harris TB, Visser M, et al; Health, Aging, and Body. Longitudinal study of muscle strength, quality, and adipose tissue infiltration. Am J Clin Nutr 2009;90:1579-1585.

21. Schafer AL, Vittinghoff E, Lang TF, et al; Health, Aging, and Body Composition (Health ABC) Study. Fat infiltration of muscle, 
diabetes, and clinical fracture risk in older adults. J Clin Endocrinol Metab 2010;95:E368-E372.

22. Zoico E, Rossi A, Di Francesco V, et al. Adipose tissue infiltration in skeletal muscle of healthy elderly men: relationships with body composition, insulin resistance, and inflammation at the systemic and tissue level. J Gerontol A Biol Sci Med Sci 2010;65:295-299.

23. Hilton TN, Tuttle LJ, Bohnert KL, Mueller MJ, Sinacore DR. Excessive adipose tissue infiltration in skeletal muscle in individuals with obesity, diabetes mellitus, and peripheral neuropathy: association with performance and function. Phys Ther 2008;88:1336-1344.

24. Sabel MS, Terjimanian M, Conlon AS, et al. Analytic morphometric assessment of patients undergoing colectomy for colon cancer. J Surg Oncol 2013;108:169-175.

25. Sabel MS, Lee J, Cai S, Englesbe MJ, Holcombe S, Wang S. Sarcopenia as a prognostic factor among patients with stage III melanoma. Ann Surg Oncol 2011;18:3579-3585.
26. Heuman DM, Abou-Assi SG, Habib A, et al. Persistent ascites and low serum sodium identify patients with cirrhosis and low MELD scores who are at high risk for early death. Hepatology 2004;40:802-810.

27. Somsouk M, Kornfield R, Vittinghoff E, Inadomi JM, Biggins SW. Moderate ascites identifies patients with low model for end-stage liver disease scores awaiting liver transplantation who have a high mortality risk. Liver Transpl 2011;17:129-136.

28. Vaughan VC, Martin P, Lewandowski PA. Cancer cachexia: impact, mechanisms and emerging treatments. J Cachexia Sarcopenia Muscle 2013;4:95-109.

29. Fujiwara N, Nakagawa H, Kudo Y, et al. Sarcopenia, intramuscular fat deposition, and visceral adiposity independently predict the outcomes of hepatocellular carcinoma. J Hepatol 2015;63:131-140.

30. Montano-Loza AJ, Angulo P, Meza-Junco J, et al. Sarcopenic obesity and myosteatosis are associated with higher mortality in patients with cirrhosis. J Cachexia Sarcopenia Muscle 2016;7:126-135. 